\title{
CrimRxiv
}

\section{The Effect of Attitudes Towards Individuals with Sexual Convictions on Professional and Student Risk Judgments}

Craig A. Harper, Rachel A. Hicks

Published on: Mar 01, 2022

DOI: $10.21428 / \mathrm{cb} 6 \mathrm{ab} 371.8 \mathrm{ee} 4513 \mathrm{~d}$

License: Creative Commons Attribution 4.0 International License (CC-BY 4.0). 
